\title{
Targeted Therapy: Can It Substitute for Chemotherapy?
}

\author{
Florian Schütz \\ Universitätsfrauenklinik Heidelberg, Germany
}

\section{Key Words}

Breast cancer - Targeted therapies - Epidermal growth factor receptors - Vascular epidermal growth factors

\section{Summary}

Every oncologist has a dream - doing more with less toxicity. Targeted therapies seem to be the key for an oncologist's dreams by defining subgroups of those patients who benefit more from a specific treatment and those who do not. For a few years now, targeted therapies have played a major role in the treatment of primary as well as metastatic breast cancer. In this article, we describe targeted therapies that already play an important role in clinical decisions in the treatment of metastatic as well as primary breast cancer. The humanised monoclonal antibody trastuzumab is a very effective agent in primary and metastatic breast cancer, but only for those patients whose tumours are overexpressing HER2/neu. Bevacizumab is an antibody directed against vascular epidermal growth factor ligand A which plays a role in angiogenesis. Up to now there is no predictive factor known for this treatment. Furthermore, we would like to give an impression of new agents and strategies under investigation like tyrosine kinase inhibitors and other small molecules.

\section{Introduction}

Every oncologist has a dream - doing more with less toxicity. Although we have achieved many improvements in treating cancer diseases by classical strategies, e.g. surgery, radiation

\author{
Schlüsselwörter \\ Brustkrebs · Zielgerichtete Therapie - Epidermale \\ Wachstumsfaktorrezeptoren · Vaskuläre epidermale \\ Wachstumsfaktoren
}

\section{Zusammenfassung}

Jeder onkologisch tätige Arzt versucht, seine Patienten so effektiv wie möglich, aber mit nur so vielen Nebenwirkungen wie nötig zu behandeln. Zielgerichtete Therapien könnten diesen Traum durch die Definition bestimmter Subgruppen verwirklichen, indem bestimmte Tumorcharakteristika als prädiktive Faktoren für diese Therapien dienen. Seit einigen Jahren spielen solche Therapien eine wichtige Rolle bei der Behandlung des primären und metastasierten Brustkrebses. In diesem Artikel beschreiben wir einerseits die zielgerichteten Therapien, die bereits Einzug in den klinischen Alltag gefunden haben: so zum Beispiel der Antikörper Trastuzumab, der gegen HER2/neu gerichtet ist und sowohl beim primären als auch beim metastasierten Brustkrebs hervorragende Erfolge erzielt hat, oder der Antikörper Bevacizumab, der gegen den Liganden A des vaskulären epithelialen Wachstumsfaktors gerichtet ist. Andererseits möchten wir einen Ausblick geben auf die Substanzen und Therapiestrategien, die momentan unter klinischer Erprobung stehen.

and cytotoxic chemotherapy, we have also reached a limit with regard to the efficacy of drugs and schedules and the tolerability of side effects.

Targeted therapies seem to be the key for an oncologist's dreams by defining subgroups of those patients who benefit

\begin{tabular}{llll}
\hline KARGER & C 2008 S. Karger GmbH, Freiburg & & Dr. Florian Schütz \\
Fax +49 7614 520714 & Accessible online at: & Universitätsfrauenklinik Heidelberg \\
$\begin{array}{l}\text { E-mail Information@Karger.de } \\
\text { www.karger.com }\end{array}$ & www.karger.com/brc & Voßstr. 9 \\
& & 69115 Heidelberg, Germany \\
& & Tel. +49 6221 567856, Fax 49 6221 483473 \\
florian_schuetz@med.uni-heidelberg.de
\end{tabular}


more from a specific treatment and those who do not. Most important in this process is the detection of special markers in tumour metabolism or tumour genetics that can predict the effect of a special drug. As a result of decades of research, new therapies are now becoming available in many cancer diseases.

However, meanwhile we do realise step by step that, even as targeted as these therapies seem to be, they do have side effects that are sometimes very uncommon for oncologists, like hypertension, skin changes, and proteinuria. Interestingly, side effects are a mirror of their effects against specific pathways, regardless of whether they are physiological or cancer specific. Learning more about tumour biology and pathways will bring us closer to our dream of 'more with less'.

For a few years now, targeted therapies have played a major role in the treatment of primary as well as metastatic breast cancer. Many clinicians are of the opinion that the invention of endocrine therapies, namely tamoxifen, has been the first step to a 'targeted' way to attack an oestrogen receptor-positive cancer disease.

In fact, the discovery and the definition of the family of epidermal growth factor receptors (EGFRs) has been the real first approach to a targeted therapy in the new understanding.

\section{EGFR Family}

Many receptors exist to control cell behaviour. In cancer cells, the expression or activity of these receptors is deranged and often overactive. The EGFR family represents a group of transmembrane receptors with an extracellular part on the tumour cell's surface and an intracellular part. Up to now there are four different receptors described: EGFR, human epidermal receptor (HER)2/neu, HER3, and HER4.

As far as we know, in breast cancer EGFR and HER2/neu are relevant. $20-25 \%$ of all primary breast cancer tumours are HER2/neu overexpressing and do have - without treatment a worse prognosis than HER2/neu-negative tumours. Although researchers have not been able to identify any activator of HER2/neu, the receptor seems to play a central role in the biology of breast cancer cells.

Receptors can be activated by special ligands, but they can also interact with other cell surface-based receptors. Both kinds of interaction lead to the activation of pathways inside the tumour cell that may lead to the expression of tumour cell characteristics like proliferation, migration, and invasion. There are two main ways to interfere with overactive receptors: antibodies to block a receptor's ligand or the receptor itself (so called 'mabs') and small molecules to block the intracellular activation of the receptor (so called 'nibs'). After years of preclinical as well as clinical studies, we know that the EGFR and HER2 pathway inside tumour cells can also be influenced. Tyrosine kinase (TK) domains are the intracellular part of the transmembrane receptor, transmitting signals from the outside to the inside of the cell. TKs can be inhibited by small molecules that are able to penetrate the cell membrane and block their enzymatic activity.

In anti-HER2 therapy, all trials do have a clear message: Only treat patients with HER2 overexpression measured by immunohistochemistry or by fluorescent in situ hybridisation (FISH). Therefore, it is most important to carefully assess the HER2 status of every breast cancer patient.

\section{Trastuzumab (Herceptin)}

Trastuzumab has been described by Slamon and colleagues in the beginning of the 1990s as a humanised monoclonal antibody against EGFR-2 (HER2/neu) which is expressed on the surface of many primary as well as metastatic breast cancer tumour cells [1].

First clinical studies in metastatic breast cancer were disappointing due to the lack of patient group selection. However, researchers found out that patients having tumours with an overexpression of HER2 seemed to benefit more from the treatment than patients with tumours with lower or without any expression.

Trastuzumab is the only medical treatment that has revealed to prolong life in metastatic breast cancer patients with HER2 overexpression in combination with chemotherapy $[2,3]$. In primary breast cancer patients, trastuzumab is one of the most effective drugs for HER2-overexpressing tumours. In combination with [4] or given sequential to chemotherapy [5], it nearly halves the number of recurrences (39-52\%) and significantly prolongs overall survival at follow-up ranging between 1 and 3 years.

Trastuzumab is well tolerated. The main toxicities consist in a reduction of the left ventricular ejection fraction with subsequent congestive cardiac failure (CCF) in $0.3-3.4 \%$ of all treated patients and anaphylactic reactions. Since CCF is a severe side effect especially in combination with anthracyclines, clinical trials of a combination therapy with trastuzumab without anthracyclines were developed. In a recently published trial with carboplatin and docetaxel, nearly no CCF was observed at all. The effectiveness of carboplatin and docetaxel in combination with trastuzumab was equivalent to the combination of anthracycline-containing chemotherapy with trastuzumab [6].

However, the most important lesson we have learned from all clinical HER2-positive trials is that only a single subgroup of patients benefits from this targeted therapy: those whose tumours overexpress HER2/neu. The others only seem to suffer from the side effects without improvement of their prognosis.

\section{Lapatinib}

The TK inhibitor (TKI) lapatinib inhibits both EGFR and HER2. Clinical trials have shown that in trastuzumab-pretreated metastatic breast cancer patients with HER2-overexpressing tumours a combination of capecitabine and lapatinib led to a better progression-free but not overall survival in 
comparison to capecitabine alone [7]. Studies with lapatinib in combination with other chemotherapies and partly with trastuzumab in primary breast cancer (PBC) are under way. Lapatinib is generally well tolerated; side effects can include diarrhoea, hand-foot-syndrome, nausea, vomiting, fatigue and rash. Long-term cardiotoxicity is not known but cardiac events are rare in trials conducted so far.

Whether lapatinib is an effective alternative to trastuzumab has to be investigated in trials with a direct head-to-head comparison. Almost more interesting would be the answer to the question whether trastuzumab plus lapatinib can inhibit the HER2/EGFR pathway more than a monotherapy of each drug.

\section{Vascular Epidermal Growth Factor Pathway}

The concept of targeting the developing vascular supply of a new tumour (anti-angiogenic therapy) was introduced by Folkman in 1971 [8]. Angiogenesis is a process that describes the physiological as well as pathological generation of new blood vessels.

While angiogenesis is a physiological process that occurs naturally and is controlled by 'on' and 'off' switches, building new blood vessels in malignant tumours seems to be an uncontrolled phenomenon. Malignant cells can alter endogenous angiogenic pathways and retard anti-angiogenic factors, thus providing an imbalance in blood vessel formation. Extensive laboratory data suggest that angiogenesis plays an essential role in breast cancer development, invasion, and metastasis [9]. Microscopic metastases are growth restricted $(<2 \mathrm{~mm})$ due to the need of oxygen and nutrients. They remain dormant until they undergo an 'angiogenic switch', presumably a result of further mutation. Hypoxia is a key signal for the induction of angiogenesis next to several other factors (interleukin-8, growth factors (EGF), oncogenes). Increased angiogenesis has been identified as an independent prognostic indicator for tumour recurrence and survival, with increased levels of angiogenesis and elevated tumour microvessel density linked with poor prognosis in multiple malignancies including breast cancer [10].

The vascular endothelial growth factor (VEGF) and its receptor (VEGFR) are key regulators of this process, promoting endothelial growth, migration, survival and blood vessel permeability [11]. Although an overexpression of VEGFR is associated with tumour progression and poor prognosis, in metastatic breast cancer VEGFR is not a predictive factor for an anti-angiogenic therapy. Anti-VEGF therapies reduce tumour vascularisation and therefore can inhibit tumour growth and metastasis. They can also reduce microvascular permeability and help to normalise irregular and leaky blood vessels and allow better delivery of chemotherapy to the tumour [12]. Published trials so far include metastatic breast cancer patients only. However, especially in locally advanced cancer disease one can think about the sense of anti-angiogenic treatments.

\section{Bevacizumab (Avastin)}

Bevacizumab was the second Food and Drug Administration (FDA)-approved humanised monoclonal antibody in metastatic breast cancer. It is directed against ligand $\mathrm{A}$ of the VEGFR.

Like in anti-EGFR therapy, in combination with chemotherapy (paclitaxel) it was successful in first-line treatment of metastatic breast cancer [13]. However, in pretreated metastatic breast cancer, a combination of capecitabine and bevacizumab showed a lack of benefit in comparison to capecitabine alone, which may represent the poor prognosis due to tumour heterogeneity as well as the choice of chemotherapy [14]. In metastatic breast cancer patients, bevacizumab's combination partner seems to play a central role, as well as the line of therapy. Combinations with several agents like docetaxel [15, 16], vinorelbin [17], carboplatin, and nabpaclitaxel [18] were positively tested.

However, in contrast to trastuzumab there is no predictive marker available that can define a subgroup of patients who benefit most from the treatment. Consequently, every patient with metastatic breast cancer can be treated in first line with bevacizumab. Bevacizumab has a very class-specific profile of side effects like hypertension and proteinuria. Its toxicity generally does not overlap with chemotherapy.

In future trials, combination partners will change as well as the time point of treatment. It was suggested that angiogenesis occurs in the very early stages of tumour development (micrometastases), which gives a strong rationale for an adjuvant anti-angiogenic treatment. The Eastern Cooperative Oncology Group is planning an adjuvant feasibility trial evaluating bevacizumab in combination with dose-dense doxorubicin and cyclophosphamide followed by paclitaxel in women with node-positive primary breast cancer.

TKIs of VEGFR are also known but are under clinical investigation (e.g. sorafenib and sunitinib). Their toxicity is characterised by fatigue, skin rashes, hand-foot-syndrome (HFS), and hypertension.

\section{Combined Targeted Therapies}

There are efforts to combine different kinds of targeted therapies to optimise progression-free as well as overall survival without chemotherapy toxicities.

\section{Combination of Different Anti-HER2 Drugs}

Whether an inhibition of the HER2 pathway by more than one agent is better than a monotherapy is an open question that will be answered by several phase II-III trials that are under way. In 2007, Baselga et al. presented at the meeting of the American Society of Clinical Oncology and at the San Antonio 
Breast Cancer Symposium preliminary results of a one-arm phase II trial combining trastuzumab and pertuzumab in HER2-overexpressing metastatic breast cancer pretreated with trastuzumab and chemotherapies [19]. Pertuzumab is also a humanised antibody against HER2/neu, but is directed against a different part of the receptor. The clinical benefit rate was $39 \%$ and the progression-free survival was significantly better, without enhancing side effects (especially CCF). These results are promising due to the relatively high efficacy in a heavily pretreated cohort.

Whether the combination of lapatinib and trastuzmab is better than each of these agents alone is under investigation in several trials, e.g. ALTO.

\section{Combination of Anti-VEGF and Anti-HER2 Pathways}

A combination of bevacizumab and HER2 receptor blocking treatment appears very reasonable due to findings in preclinical and clinical studies that HER2 seems to play a central role in the regulation of VEGF [20, 21]. Several studies have demonstrated that blockade of the EGFR resulted in an antiangiogenic effect [22]. In a preclinical study, exposure to trastuzumab significantly decreased VEGF in HER2-overexpressing cells [23]. In vivo experiments have shown a reduction in xenograft volume using a combination of trastuzumab and bevacizumab compared with the single-agent control. Furthermore, in a cohort of 611 patients with primary breast cancer and a median follow-up of $>50$ months, there was a significant positive association between HER2 and VEGF expression [24]. On the other hand, it was shown that VEGF is also able to regulate EGFR pathways. Data have suggested that an increased production of VEGF represents one mechanism by which tumour cells escape anti-EGFR monoclonal antibody therapy [25].

A phase I trial has evaluated the tolerability of the combination of bevacizumab with trastuzumab. It was determined that co-administration of these two humanised monoclonal antibodies did not alter the pharmacokinetics of either agent. The clinical responses were promising [26].

A phase III trial is under way (bevacizumab, trastuzumab and docetaxel as first-line therapy in HER2-positive metastatic breast cancer (AVEREL trial)).
One trial has tested the combination of bevacizumab and erlotinib, an EGFR TKI, in metastatic breast cancer. This combination demonstrated activity and also found that changes in circulating endothelial cells and circulating tumour cells may correlate with response to this combination [27].

\section{Combination of Anti-VEGF or Anti-HER2 Pathway with Other Pathway Inhibitors}

Recently, new small molecules have been designed to block pathways deeper inside the tumour cell metabolism (e.g. phosphatase and tensin homologue deleted on chromosome 10 (PTEN), phosphatidylinositol 3-kinase (PI3K), mammalian target of rapamycin (mTOR) inhibitors). Theoretically, these new agents are also possible combination partners to chemotherapies as well as targeted therapies, but their value in cancer treatment has to be investigated in clinical trials.

\section{Can Targeted Therapies Substitute for Chemotherapy?}

So far, all trials investigating targeted therapies have shown a clear benefit from a combination of new molecules with chemotherapy. Monotherapies seem to have benefits as well, but they cannot reach the efficacy of combination therapies. Consequently, targeted therapies cannot substitute for chemotherapy today.

However, in the near future, we will have to deal with major clinical problems:

- What are the best 'targeted' combination partners in which setting? Will we still need anthracyclines for all patients in the adjuvant setting or only for some? How shall we deal with adjuvant pretreatment in the metastatic setting?

- What is the best agent in which setting? TKIs or antibodies against HER2 or both? Anti-VEGF agents for all or only for subgroups?

- What will we do when there is more than one targeted agent approved for the same clinical situation and when there is no head-to-head comparison available answering the important question which one is the optimal one?

Chemotherapy will always play a major role in breast cancer treatment. However, its role is under investigation!

\section{References}

1 Pegram MD, Pauletti G, Slamon DJ: HER-2/neu as a predictive marker of response to breast cancer therapy. Breast Cancer Res Treat 1998;52:65-77.

$\checkmark 2$ Slamon DJ, Leyland-Jones B, Shak S, Fuchs H, Paton V, Bajamonde A, Fleming T, Eiermann W Wolter J, Pegram M, Baselga J, Norton L: Use of chemotherapy plus a monoclonal antibody against HER2 for metastatic breast cancer that overexpresses HER2. N Engl J Med 2001;344:783-792.

-3 Marty M, Cognetti F, Maraninchi D, Snyder R, Mauriac L, Tubiana-Hulin M, Chan S, Grimes D, Antón A, Lluch A, Kennedy J, O'Byrne K, Conte P, Green M, Ward C, Mayne K, Extra JM: Randomized phase III trial of the efficacy and safety of trastuzumab combined with docetaxel in patients with HER2-positive metastatic breast cancer administered as first line treatment: the M77001 study group. J Clin Oncol 2005;23:4265-4274.

$\checkmark 4$ Romond EH, Perez EA, Bryant J, Suman VJ, Geyer CE Jr, Davidson NE, Tan-Chiu E, Martino S, Paik S, Kaufman PA, Swain SM, Pisansky TM, Fehrenbacher L, Kutteh LA, Vogel VG, Visscher DW, Yothers G, Jenkins RB, Brown AM, Dakhil SR, Mamounas EP, Lingle WL, Klein PM, Ingle JN, Wolmark N: Trastuzumab plus adjuvant chemotherapy in HER2 positive breast cancer. N Engl J Med 2005;353:1673-1684.
5 Piccart-Gebhart MJ, Procter M, Leyland-Jones B, Goldhirsch A, Untch M, Smith I, Gianni L, Baselga J, Bell R, Jackisch C, Cameron D, Dowsett M, Barrios $\mathrm{CH}$, Steger $\mathrm{G}$, Huang $\mathrm{CS}$, Andersson $\mathrm{M}$, Inbar M, Lichinitser M, Láng I, Nitz U, Iwata $\mathrm{H}$ Thomssen C, Lohrisch C, Suter TM, Rüschoff J, Suto T, Greatorex V, Ward C, Straehle C, McFadden E, Dolci MS, Gelber RD; Herceptin Adjuvant (HERA) Trial Study Team: Trastuzumab after adjuvant chemotherapy for operable HER2 positive breast cancer. N Engl J Med 2005;353:1659-1672. 
6 Slamon DJ, Eiermann W, Robert N: Phase IIIrandomized trial comparing doxorubicin and cyclophosphamide followed by docetaxel (ACT) with doxorubicin and cyclophosphamide followed by docetaxel and trastuzumab (ACTH) with docetaxel, carboplatin and trastuzumab (TCH) in HER2 positive early breast cancer patients: BCIRG 006 study. Breast Cancer Res Treat 2005;94 (suppl 5).

7 Geyer CE, Forster J, Lindquist D, Chan S, Romieu CG, Pienkowski T, Jagiello-Gruszfeld A, Crown J, Chan A, Kaufman B, Skarlos D, Campone M, Davidson N, Berger M, Oliva C, Rubin SD, Stein S, Cameron D: Lapatinib and capecitabine for HER2positive advanced breast cancer. N Engl J Med 2006;355:2733-2743.

8 Folkman J: Tumor angiogenesis: therapeutic implications. N Engl J Med 1971;285:1182-1186.

$\checkmark$ Schneider BP, Miller KD: Angiogenesis of breas cancer. J Clin Oncol 2005;23:1782-1790.

10 Toi M, Hoshina S, Takayanagi T, Tominaga I: Association of vascular first endothelial growth factor expression with tumor angiogenesis and with early first relapse in primary breast cancer. Jpn J Cancer Res 1994;85:1045-1049.

11 Schuetz F, Sohn C, Schneeweiss A: Bevacizumab in the treatment of breast cancer. Breast Care 2006; 2:62-63.

12 Jain RK: Normalization of tumor vasculature: an emerging concept in antiangiogenic therapy. Science 2005;307:58-62.

13 Miller K, Wang M, Gralow J, Dickler M, Cobleigh M, Perez EA, Shenkier T, Cella D, Davidson NE: Paclitaxel plus bevacizumab versus paclitaxel alone for metastatic breast cancer. N Engl J Med 2007; 357:2666-2676.

14 Miller KD, Chap LI, Holmes FA, Cobleigh MA, Marcom PK, Fehrenbacher L, Dickler M, Overmoyer BA, Reimann JD, Sing AP, Langmuir V, Rugo HS: Randomized phase III trial of capecitabine compared with bevacizumab plus capecitabine in patients with previously treated metastatic breast cancer. J Clin Oncol 2005;23: 792-799.
15 Ramaswamy B, Elias AD, Kelbick NT, Dodley A, Morrow M, Hauger M, Allen J, Rhoades C, Kendra K, Chen HX, Eckhardt SG, Shapiro CL: Phase II trial of bevacizumab in combination with weekly docetaxel in metastatic breast cancer patients. Clin Cancer Res 2006;12:3124-3129.

16 Miles D, Chan A, Romieu G, Dirix LY, Cortes JA, Pivot P, Tomczak T, Taran T, Harbeck N, Steger GG: Randomized, double-blind, placebo-controlled, phase III study of bevacizumab with docetaxel or docetaxel with placebo as first-line therapy for patients with locally recurrent or metastatic breast cancer (MBC): AVADO. J Clin Oncol 2008(suppl): abstr 1011.

17 Burstein H, Parker L, Savoie J, et al: Phase II trial of the anti-VEGF antibody bevacizumab in combination with vinorelbine for refractory advanced breast cancer. Breast Cancer Res Treat 2002;76: S115(abstr 446).

18 Bernstein JA, Schubbert T, Kong K, Mehta RS: Weekly carboplatin and nab-paclitaxel plus trastuzumab, or plus or minus bevacizumab: clinical response in patients with breast cancer. J Clin Oncol 2007;24(suppl):abstr 10699.

19 Baselga J, Cameron D, Miles D, et al: Objective response rate in a phase II multicenter trial of pertuzumab (P), a HER2 dimerization inhibiting monoclonal antibody, in combination with trastuzumab (T) in patients (pts) with HER2-positive metastatic breast cancer (MBC) which has progressed during treatment with T. J Clin Oncol 2007;25, No. 188 (suppl):abstr 1004.

20 Koukourakis MI, Giatromanolaki A, O’Byrne KJ, Cox J, Krammer B, Gatter KC, Harris AL: bcl-2 and c-erbB-2 proteins are involved in the regulation of VEGF and of thymidine phosphorylase angiogenic activity in non-small-cell lung cancer. Clin Exp Metastasis 1999;17:545-554.
1 Clarke K, Smith K, Gullick WJ, Harris AL: Mutant epidermal growth factor receptor enhances induction of vascular endothelial growth factor by hypoxia and insulin-like growth factor-1 via a PI3 kinase dependent pathway. Br J Cancer 2001;84: 1322-1329.

22 Bruns CJ, Solorzano CC, Harbison MT, Ozawa S, Tsan R, Fan D, Abbruzzese J, Traxler P, Buchdunger E, Radinsky R, Fidler IJ: Blockade of the epidermal growth factor receptor signaling by a novel tyrosine kinase inhibitor leads to apoptosis of endothelial cells and therapy of human pancreatic carcinoma. Cancer Res 2000;60:2926-2935.

23 Epstein M, Ayala R, Tchekmedyian N, et al: HER2 overexpressing human breast cancer xenografts exhibit increased angiogenic potential mediated by vascular endothelial growth factor (VEGF). Breast Cancer Res Treat 2002;76:S143(abstr 570).

24 Konecny GE, Meng YG, Untch M, Wang HJ, Bauerfeind I, Epstein M, Stieber P, Vernes JM, Gutierrez J, Hong K, Beryt M, Hepp H, Slamon DJ, Pegram MD: Association between HER-2/neu and vascular endothelial growth factor expression predicts clinical outcome in primary breast cancer patients. Clin Cancer Res 2004;10:1706-1716.

25 Viloria-Petit A, Crombet T, Jothy S, Hicklin D, Bohlen P, Schlaeppi JM, Rak J, Kerbel RS: Acquired resistance to the antitumor epidermal growth factor receptor-blocking antibodies in vivo: A role for tumor angiogenesis. Cancer Res 2001; 61:5090-5101.

26 Pegram M, Yeon C, Ku N, et al: Phase I combined biological therapy of breast cancer using two humanized monoclonal antibodies directed against HER2 proto-oncogene and vascular endothelial growth factor (VEGF). Breast Cancer Res Treat 2004;88:S124(abstr 3039).

27 Rugo H, Dickler M, Statt J, et al: Circulating endothelial cell (CEC) and tumor cell (CTC) analysis in patients receiving bevacizumab and erlotinib for metastatic breast cancer (MBC). Breast Cancer Res Treat 2004;88:5142(abstr 3088). 